\title{
Cell Respiration
}

National Cancer Institute

\section{Source}

National Cancer Institute. Cell Respiration. NCI Thesaurus. Code C17894.

A two-stage process in which molecules are oxidized to produce energy. In the first stage, glucose is converted to pyruvic acid via the glycolytic pathway. Subsequently, pyruvic acid is metabolized to ultimately yield carbon dioxide and water. 